\title{
PROCEDIMENTO OPERACIONAL PADRÃO PARA MANUTENÇÃO PREVENTIVA DE BERÇO AQUECIDO FANEM.
}

\author{
N. M. V. Alves*, C. M. Godoi**, M. F. Rezende**, W. M. Moura, R. O. Santi**, S. T. Milagre* \\ *Universidade Federal de Uberlândia, Faculdade de Engenharia Elétrica, Uberlândia, Brasil \\ **Setor de BioEngenharia HCU-UFU, Uberlândia, Brasil \\ e-mail: nyallamary@gmail.com
}

\begin{abstract}
Resumo: A evolução tecnológica introduziu nos Estabelecimentos Assistenciais de Saúde (EASs) uma grande quantidade e variedade de equipamentos médicos. Entretanto, para mantê-los com alta disponibilidade de uso são necessários procedimentos adequados de manutenção. Assim, a necessidade de adaptar-se às imposições do mercado levou à evolução da manutenção ao longo do tempo. O Procedimento Operacional Padrão (POP) tornou-se uma ferramenta eficaz nos setores de manutenção, principalmente em relação às manutenções preventivas dos EASs visando reduzir o tempo e os custos, com novos aparelhos, e, em contrapartida, garantir a efetividade das manutenções e o bem-estar do paciente. Nesse contexto, o presente estudo propõe a elaboração de um POP de manutenção preventiva em Berços Aquecidos. A realização deste trabalho ocorreu em um Hospital de grande porte situado na cidade de Uberlândia, Minas Gerais, Brasil, conforme autorização e acompanhamento técnico para realização de quaisquer procedimentos.

Palavras-chave: Manutenção preventiva, Procedimento Operacional Padrão, Berço Aquecido.
\end{abstract}

\begin{abstract}
The technological evolution introduced in Care Facilities Health (SAEs) a large amount and variety of medical equipment. But, to keep them with high availability of use, some appropriate procedures of maintenance are necessary. Thus, the need to adapt to market impositions led to the evolution of maintenance over time. The Standard Operating Procedure (SOP) has become an effective tool in the maintenance sectors, especially in relation to preventive maintenance of SAEs to reduce the time and costs with new equipment, and on the other hand, ensure the effectiveness of maintenance and the patient's well-being. In this context this study proposes the development of a SOP of preventive maintenance on heated cribs. This work took place in a large hospital located in Uberlandia, Minas Gerais, Brazil, according to authorization and technical support to fulfillment any procedure
\end{abstract}

Keywords: preventive maintenance, standard operational procedure, heated crib.

\section{Introdução}

A manutenção preventiva sofreu, ao longo dos anos, diversas e profundas transformações a fim de adaptar-se às exigências do mercado, que determinaram, em virtude da globalização e da concorrência internacional, a necessidade de redução de custos, promovendo o aperfeiçoamento dessa área [1].

Entretanto, embora a manutenção preventiva seja necessária para ampliar a vida útil do equipamento com a consequente redução de custos e aumento da sua segurança e desempenho, a limitação de recursos materiais, humanos e financeiros tem restringido o desenvolvimento de programas de manutenção preventiva e diversos grupos de manutenção de equipamentos hospitalares, principalmente no Brasil [2].

O Procedimento Operacional Padrão (POP) surgiu, então, como alternativa à otimização de revisões de equipamentos médico-hospitalares. O POP consiste em uma sequência de etapas e testes que devem ser executados pelo operador ou profissional que visam garantir o rendimento esperado do equipamento em determinada tarefa [3].

Tais procedimentos tornam-se também necessários em razão de diversos dados estatísticos que apontam a falha humana, durante procedimentos de manutenção, como principal causa do mau funcionamento de equipamentos médicos. O POP tem por objetivo, portanto, auxiliar o técnico na análise para detecção de falhas, no conhecimento sobre a urgência da realização do serviço, no estabelecimento de uma rotina de manutenção preventiva e na obtenção do nível de confiabilidade exigido, uma vez que uma manutenção inadequada poderá colocar em risco a vida do paciente [2].

Ademais, o POP visa padronizar e minimizar a ocorrência de desvios na execução de tarefas fundamentais para o funcionamento correto do processo, assegurando que as ações tomadas para garantir a qualidade sejam sempre às mesmas, aumentando assim a previsibilidade dos resultados e minimizando as variações causadas por imperícias e adaptações aleatórias [4].

$\mathrm{O}$ berço aquecido trata-se de um equipamento amplamente utilizado em UTI Neonatais e seu bom funcionamento é essencial, principalmente, para aumentar chances de sobrevida de bebês prematuros. Logo é de extrema importância garantir que o aquecimento e a segurança deste aparelho estejam dentro dos padrões estabelecidos em normas. 
Os berços são constituídos por um elemento de aquecimento que gera energia radiante, um termistor aplicado em uma área do corpo do recém-nascido que esteja exposta ao calor e um controlador de temperatura proporcional que realiza a tomada de decisão por desligar ou ligar o aquecedor. Assim, uma extremidade do termistor é associada a um dos braços de uma ponte resistiva, com o resistor de referência conectado à outra extremidade da ponte. A saída da ponte é amplificada, e a tensão resultante é proporcional à diferença de temperatura entre o termistor e o resistor de ajuste [2].

A fonte de energia de radiação em condições inadequadas de funcionamento pode emitir, por exemplo, energia de faixas próximas ao infravermelho podendo acarretar lesões nas retinas e nas córneas dos bebês.

Desta forma, o presente trabalho objetiva o elaborar um POP para manutenção preventiva de berço aquecido que integra o patrimônio tecnológico de um Estabelecimento Assistencial de Saúde (EAS) de grande porte.

\section{Materiais e métodos}

O presente trabalho constitui-se de várias etapas a iniciar-se por meio de estudo sobre a necessidade de elaboração de POPs de diferentes equipamentos presentes em um EAS de grande complexidade. O estudo foi realizado no setor de Engenharia Clínica deste estabelecimento e contou com a colaboração de diferentes funcionários do setor.

Com auxilio e baseado nas normas legais e vigentes no Brasil, e conhecendo as necessidades e dificuldades dos trabalhadores do setor de Engenharia Clínica responsáveis pelas manutenções, escolheu-se o equipamento a ser trabalhado.

As etapas foram estabelecidas juntamente com engenheiros, estagiários e responsáveis técnicos que direcionaram e atribuíram os testes a serem executados.

Deu-se início então à elaboração do POP, onde cada etapa foi cuidadosamente anotada e fotografada.

Após a elaboração do POP, o mesmo foi colocado em teste pelos profissionais do setor de Engenharia Clínica. Assim, foram efetuadas as revisões a fim de elaborar um documento acessível e claro a todos.

\section{Resultados e Discussões}

Feitas todas as alterações o documento (figura $1 \mathrm{e}$ figura 2) foi redigido, concluído, e entregue ao setor de Engenharia Clinica do EAS.

Ao ser implementado, o POP obteve feed-back positivo dos profissionais do setor que disseram compreende-lo de modo inequívoco. Dessa maneira, o documento foi arquivado no sistema do setor para que possa ser consultado quando necessário.

\section{Conclusão}

Os POPs se operados de modo correto como orientado, reduz as chances eventos adversos com aparelhos. Além disso, atribui maior segurança ao equipamento e ao funcionário, posto que os testes foram previamente selecionados e testados.

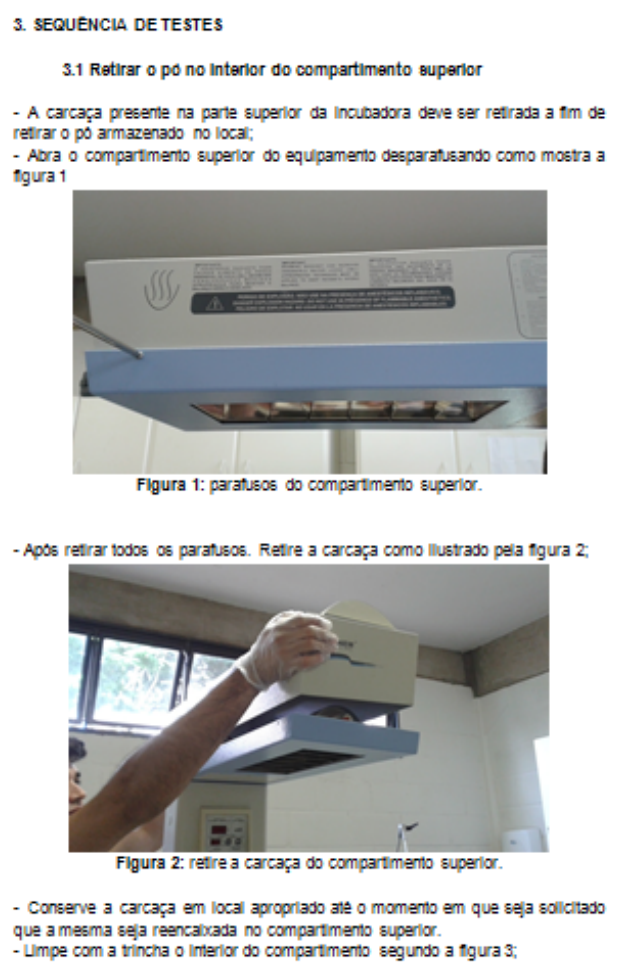

Figura 1: Procedimento Operacional Padrão (POP) do Berço Aquecido da marca Fanem.

O método de checagem passo a passo reduz ainda a possibilidade de que alguma etapa ou teste sejam ignorados comprometendo o desempenho eficaz do equipamento.

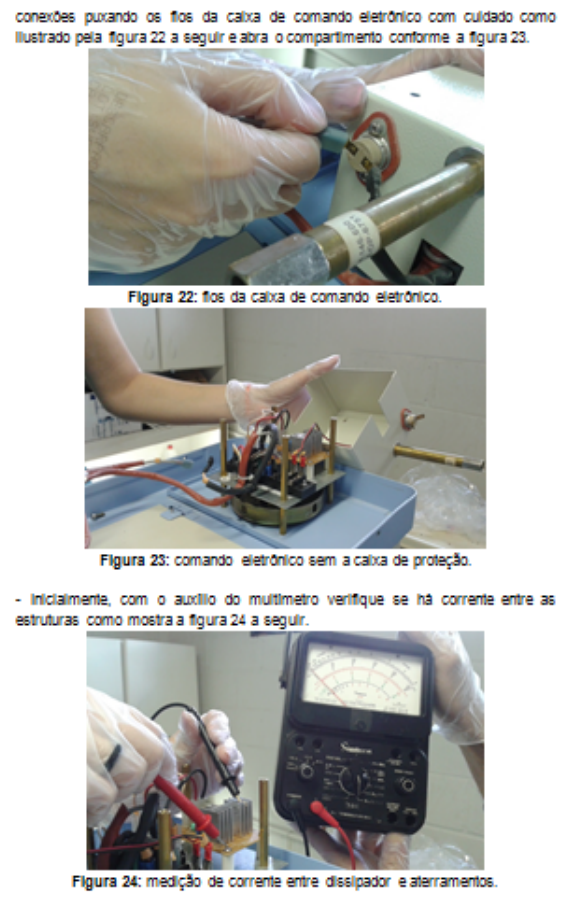


Figura 2: Procedimento Operacional Padrão (POP) do Berço Aquecido da marca Fanem

Através da execução do estudo observou-se que a introdução do POP ao setor de manutenção reduz a necessidade treinamento de pessoal para a manipulação dos aparelhos, visto que, dispõe de uma linguagem acessível e apresentar ilustrações que facilitam o entendimento do técnico, além de diminuir o tempo gasto para realização da manutenção.

Além disso, a execução correta e consciente do POP proporciona uma manutenção efetiva que fomentará a limitação da probabilidade de substituição do dispositivo.

\section{Agradecimentos}

Os autores agradecem à CAPES, FAPEMIG, CNPq e ao HCU-UFU pelo apoio prestado.

\section{Referências}

[1] Lucatelli MA. Proposta de Aplicação de Manutenção Centrada em Confiabilidade em Equipamentos Médico-Hospitalares. Univrsidade Federal de Santa Catarina, Outubro 2002, p.17-18.

[2] BRASIL. MINISTÉRIO DA SAÚDE. Equipamentos médico-hospitalares e o gerenciamento da manutenção - Capacitação a distância. Série F. Comunicação e Educação em Saúde. Brasília: Ministério da Saúde. 2002.

[3] Paula JMM de, Milagre ST. Desenvolvimento de procedimentos operacionais padrôes (POPs) para operação de equipamentos médico-hospitalares. Anais VIII Simpósio em Engenharia Biomédica. 2015; p.194-198

[4]Castro BNR de, Alves CM, Viginéski IWS, Mazotti NL, Milagre ST, Godoi CM de. Procedimento Operacional Padrão para Manutenção Preventiva de Estações de Anestesia. Anais VIII Simpósio em Engenharia Bimédica. 2015; p.128-132 